\title{
Smart grids, prosumers and energy management within a smart city integrated system
}

\author{
Marco SAVASTANO \\ Sapienza University of Rome, Faculty of Economics, Management Department, Rome, Italy \\ marco.savastano@uniromal.it \\ Marta-Christina SUCIU \\ Bucharest University of Economic Studies, Bucharest, Romania \\ christina.suciu@economie.ase.ro \\ Irina GORELOVA \\ Sapienza University of Rome, Faculty of Economics, Management Department, Rome, Italy \\ irina.gorelova@uniromal.it \\ Gheorghe-Alexandru STATIVĂ \\ Bucharest University of Economic Studies, Bucharest, Romania \\ alexstativa95@gmail.com
}

\begin{abstract}
Due to a significant increase in electricity consumption globally, governments have to look and to identify better, more efficient and effective alternatives and sustainable energy sources to meet this high demand. This becomes more and more important in the context of implementing modern approaches such as those that might be applied in cases of smart cities and cultural and creative communities. Electricity can be produced based on conventional sources, but also on an emergent use of renewable sources. The electricity grid is usually designed as unidirectional. We consider that in case of smart cities and creative-innovative communities there is a need to implement mostly new smart grids that are bidirectional. This may allow and support the emergency of a new type of electricity user, called "prosumers", who produces electricity from renewable sources, next uses \& shares them smartly within the smart grid and finally stores them. Globally, photovoltaic energy prosumers are considered one of the most important actors in the energy transition and seem to be ready to introduce significant amounts of electricity within the grid. We anticipate that people living in households in smart cities and communities among most regions of the world will tend in the future to improve their self-consumption from the production of smart energy. This paper supports the idea that using mostly electricity from renewable alternative sources, especially solar, can be also developed with the help of households acting within smart cities and communities. The paper will also present briefly an overview of the scientific literature dedicated to this topic. We will also provide further interesting insights through a number of case studies representing good practices regarding prosumers in Italy and Romania.
\end{abstract}

Keywords: smart city, smart grid, prosumer, solar panels, bi-directional network.

\section{Introduction}

Smart city vision concerns the integration of information and communication technology (ICT), and various physical devices connected to the network (the Internet of things or IoT) such as to better connect to citizens and improve the efficiency \& effectiveness of city functionality.

The main expected benefits from becoming a "smart" community such as a smart city are: efficiency, sustainability, social inclusion $\&$ participation to the whole community activities contributing also to a better quality of life for its members (Bosch et al., 2017). The four axes 
along which a city can to be defined "smart" based on and efficient \& effective use of its available resources (including both tangible and intangible assets such as: social and cultural capital, financial capital, natural resources, ITC) are as follows (Neumann et al., 2015):

- People: in terms of improving the quality of life of the community' inhabitants, workers, students and other people including potential visitors mostly in the case of cultural \& creative communities.

- Planet: by significantly improving its resource efficiency, decreasing the pressure on the environment (in terms of green economics' principles) and by increasing its resiliency.

- Prosperity: by building an innovation \& creative-driven community where each of its members has equal opportunities to explore and share its competencies $\&$ talents such as to contribute to the well-being of the whole community.

- Governance: fostering a well-developed local democracy.

Smart city technologies - mostly ITC and Internet of things (IoT) allows and facilitate city policy makers to interact directly with the whole community. A more functional and operational city infrastructure can also contribute to better identify what is happening within the community and how the city is evolving. IoT enhances the connectivity of different devices. It results in a connected network of smart devices (defined also in terms of digital ecosystems) working in tandem with Big Data. IoT solutions offer effective and efficient solutions supporting the development of people core capabilities and as a consequence more functionality within smart cities \& creative-innovative communities. IoT solutions may refer mainly to: energy, waste, water, public transport, parking management. A smart allocation and use of energy resources (mostly of the alternative one) can be facilitated based on the application of smart grid concept. Smart grid facilitate and improve communication and the flow of information regarding smart networks. Smart Grid is a technological transformation that illustrates a shift from a conventional electric grid, electro-mechanically controlled system, towards a smart, intelligent, and electronically controlled system (Shaukat et al., 2018). It may solve multiple issues like power failures and waste of energy. The smart energy-controlling devices installed within households from smart cities and creative-innovative communities facilitate an effective monitoring of energy usage through, for instance, a smartphone-based application.

The Smart Grid is not just about utilities and technologies; it is about providing the information and tools people need to make choices about how they use the energy. Many people already manage activities such as personal banking from their own home on computer. Thus it is not too difficult to imagine how people will soon manage their home electricity in a similar way. A smart grid will enable an unprecedented increase of the level of consumer participation. A Smart Grid consists of millions of pieces and parts-controls, computers, power lines, and new technologies and equipment (briefly illustrated in figure 1). 


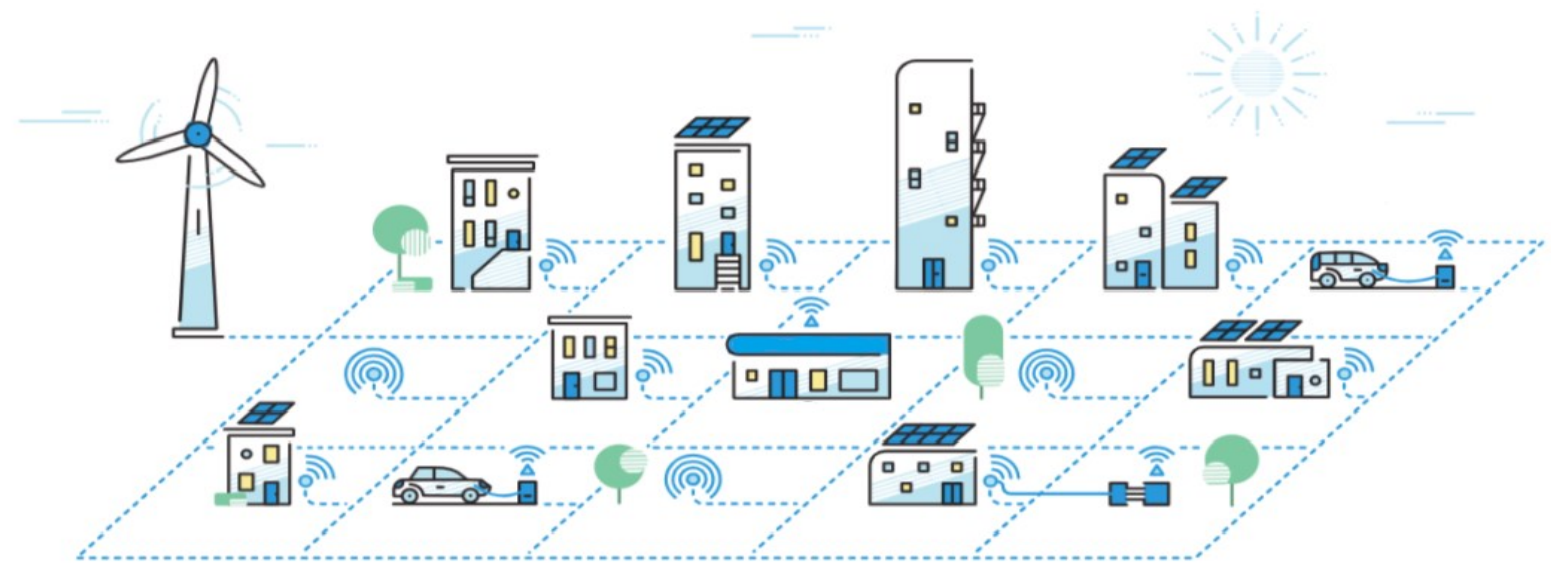

E $\mid 1123$

Figure 1. Smart City - Integrated system. Smart grid. Energy management

Source: https://www.smartgrid.gov.

The implementation of Smart Grids integrated systems within cities and mostly in smart cities provokes significant shifts in municipal electricity supply systems and considerably influences consumer \& producer behavior (in line with prosumer vision). Installation of many small power-generating sites, decentralized energy distribution together with small-scale energy transmission and, consequently, bi-directional distribution all together create a new type of electricity consumer - called prosumer, proactive and independent, who can both consume and produce electricity.

Prosumers are not only private individuals, who use electricity, produced from their own electrical power source (usually solar panels or micro combined heat and power generators), but also communities, companies and public actors, such as schools, hospitals etc. (Šajn, 2016). Prosumers and bi-directional smart grids are new concepts that have the potential to fundamentally change the traditional approach regarding electricity generation, distribution and storage.

Globally, demand for electricity is on an upward trend. According to the International Energy Outlook 2019 (IEO,2019), electricity consumption in non-OECD countries is estimated to increase in average by approximately $70 \%$ in the period $2018-2050$. This anticipated growth is mainly based on an estimated economic growth, high access to commercial energy. The consumption of energy in the OECD states is anticipated to increase more slowly, by about $15 \%$ in average corresponding to the whole period 2018-2050, due to the improvement of energy efficiency specific in the case of OECD countries. Overall, electric power consumption is estimated to increase in average by approximately 50\% globally, between 2018 and 2050 (IEO,2019).

Traditionally, electricity is produced mainly from conventional sources, respectively from coal, natural gas, nuclear and fuel. Producing electricity based on conventional sources affect the quality of environment (due to pollution, greenhouse gas emissions and global warming). In order to face the growth of demand for electricity consumption, international experts highlight the importance of using on a large scale renewable energy sources. There is a trend according to which the unidirectional model of the electricity network, having as a supplier-user sense, will be step by step transformed and replaced by a bi-directional model. 
The bi-directional model has a double supplier-user and respectively user-supplier sense, acting within an intelligent network specific (Gharavi \& Ghafurian, 2011).

The smart grid refers mostly to an electrical system that uses informational, two-ways communication technologies, which are cyber security, due to which electricity consumption is safe, efficient and sustainable. Within this smart networks formed by smart grids, users are able to generate electricity, share it with other consumers and finally store it.

Due to the massive technological progress happening during last decades and years, the urban life within smart cities and communities had faced a lot of challenges and suffered deep transformations. In the case of the recent developments of smart cities and creative-innovative communities, there was a high availability and a massive use of information and communication technologies (ICTs) in the urban environment. In urban systems, mostly in the case of smart cities a lot of changes have been observed, due to advance technologies, such as ICT, as well as their increasing performances in terms of durability and functionality. The information \& core competences \& knowledge exchange allows for local significant changes on the level of the whole community, many times being caused also by an important development of knowledgebased and learning organizations. These kind of organizations request also a better use of intangible assets such as intellectual capital, knowledge, people creative' potential and correspondingly a more efficient and effective management of both tangible and intangible resources based on the use of ITC. Despite the fact that energy consumption in smart cities is still at a high level, its quality can be significantly improved by developing smart grids and by the emergence of larger number of prosumers manifesting on different levels from residential to public.

This paper is structured as follows. The first section offers an overview of the literature concerning mostly the role and behavior of prosumers within the context of a smart city project. Second section provides a brief description of the methodology. Section 3 presents the results and discussion of some representative examples of smart cities in Italy and Romania such as to provide some best practices of the development of such projects in EU countries. Section 4 concludes the paper with implications for energy policies in smart cities, together with limitations and further research paths.

\section{Brief literature review}

The energy sector has undergone transformations due to the increase of the demand for electricity, as well as the reduction of the production of electricity from conventional sources. Households, as well as other users in some cases became "prosumers".

The first author who seems to introduce this term was Alvin Toffler, in 1981 (Toffler \& Alvin, 1981). The author defined the prosumer as the category of people who produce part of the services or goods they consume. This paper focuses on how we can apply the prosumers approach in the electricity sector.

Electricity users become consumers when they use local production capacity and are considered as producers when they transmit electricity produced by solar panels or wind turbines through the local network mostly under the auspices of the emergent implementation of smart cities including smart grid' vision. Zafar et al. (2018) defines the prosumers as "the consumers who also produce and share surplus energy with grid and other users" (Zafar, et al.,p.82).

Thanks to smart grids vision, that allows bidirectional energy, information and knowledge flows between the energy user and the utility grid, energy users are able not only to 
consume energy but also to generate and share it with the utility grid or with other energy consumers (Rathnayaka et al., 2011). The authors introduced the concept of prosumer community as a major improvement to the simple prosumer groups. Prosumer-communities aggregates and gather together prosumers with similar interests and behaviors (e.g. in terms of energy sources, amount of energy supplied to the grid, etc). Those communities aim to achieve a common goal, such as to achieve at least the minimum amount of energy requested by utility provision, or the minimum amount of energy required to obtain higher bargaining power manifested on the energy market. The authors also identified some important factors that directly influence the energy sharing behaviors of prosumers. The most important are energy storage capacities; technological advancements in emerging renewable energy systems; energy trading possibilities (Rathnayaka et al., 2011).

More recently, concerning the co-creation of distributed flexibility, Kubli et al. (2018) conducted a series of choice experiments with several actual and potential flexible prosumers across three domains of energy use (i.e. PV-battery, Electric vehicles and Heat pumps). The study confirmed a general positive willingness to co-create flexibility; more in detail, prosumers with PV plus battery systems and electric vehicle owners appeared to be more willing to provide flexibility than heat pump owners. Hence, the authors found that prosumers do not prefer flexibility per se, but they are willing to accept certain levels of inconvenience in exchange for higher utility through specific product attributes (Kubli et al., 2018). In addition, prosumers can be considered not only as important stakeholders of the smart grids, but also as playing a crucial part in the management of peak demand. On this topic, the paper of Zafar et al. (2018) presents a comprehensive review of Prosumers based Energy Management and Sharing (PEMS) paradigm in a smart grid environment and associated impact on power system reliability and energy sustainability. The authors focused on the two key elements involved in the process of energy sharing among prosumers - ICTs and optimization techniques - that resulted essential for the formation of prosumer communities and energy districts.

The study of Morstyn and McCulloch (2018) introduces the concept of multi-class energy management, which allows energy to be treated as a heterogeneous product, based on attributes of its sources that are perceived by prosumers to have value. This was used for a Peer-To-Peer $(P 2 P)$ energy market platform which coordinates energy trading between distribution network prosumers and the wholesale electricity market. This platform adds value by accounting for individual prosumer energy preferences, which could be of different nature (financial, social, philanthropic or environmental). There are numerous opponents of the two-way electricity network, but in the same time there are also many supporters. The distrust manifested sometime between the central actors of the energy industry is motivated by the interests of the local businesses, without taking into account the general interests of the company. For instance, Kvellheim supports the idea that the electricity produced by buildings must be perceived by opponents as being significant on the issue of the mainstream concept (Kvellheim, 2017).

According to Olkkonen, prosumers are considered different from ordinary consumers because they are considered as persons who are engaged in the micro-production of electricity. When analyzing the prosumer, it is important to analyze the relationships between the user and the electric companies, as the customers may have different relationships with the energy companies.

The main difference between the smart energy networks that are bi-directional shows that prosumers help to improve the efficiency \& effectiveness of the energy systems, compared to the unidirectional energy network. Two-way networks have communication technologies and 
intelligent devices that help to store energy surplus and to balance local demand for electricity (Parag \& Sovacool, 2016). The transition from passive consumers to prosumers (who are called also active consumers), brings certain economic benefits, but they also contribute to preserve and even to improve the quality of the environment (Potdar et al., 2018). Among the factors influencing this transition are the new technologies, such as advanced infrastructure, smart devices, smart controls. The implementation of these different and complex smart devices within smart cities may contribute to reach a more efficient \& effective use of resources mostly in the long run.

\section{Methodology}

This paper aims at illustrating the relationship between smart cities and energy prosumers. It is focusing on illustrating how the unidirectional energy networks can be transformed into bidirectional networks, reducing pollution in communities, cities and regions, as well as transforming the production of electricity from conventional-based sources, into renewable \& alternative electricity sources, to be friendly used taking also into account the quality of the environment.

Our research highlights the impact of prosumers and their behavior on smart cities development with a special reference to energy management issues based on the smart grid implementation within the local communities. The main research question is:

What is the role of local \& public administration decision makers from smart cities for developing and better managing the interdependence between prosumers and smart grids?

In order to address our research question, the following research objectives were set:

- to provide a clear understanding of the role and behavior of prosumers;

- to identify and investigate what are the most effective incentives and actions that might be applied in order to promote the involvement of prosumer / self-consumption behavior;

- to explore and compare some best practices examples of smart cities in EU countries.

Discussion concerning how to implement innovative solutions within energetic field mostly in Smart Cities has to find a balance between theoretical research and practical application. Therefore, it requires the division of the research approach into two methods: theoretical and empirical. With regard to the theoretical approach, the authors aim to collect and analyze both scientific articles on the energy concepts of Smart Cities and reports on Smart City projects, initiatives and initiatives by municipalities, governmental and local institutions and large companies with regard to smart-grid and energy management concepts. The literature review shows that the topic is well-studied, but the authors hope that a more in-depth analysis of the collected documents will however allow to improve some interesting aspects, in order to find a resolution that is not only theoretical, but in the same time useful to support the further implementations in smart cities and the cities that are in the course of development following a smart road.

These issues are looking mostly for the role of government, citizens incentives, knowledge and skills in building efficient energy management system for smart city projects in Europe and in particular in Italy and Romania. In order to illustrate the level of development of prosumer initiatives in Italy and Romania the authors have chosen the cities of Bologna in Italy and correspondingly Cluj-Napoca Alba-Iulia in Romania. 
These cities are both financial, industrial, academic centers in their countries and all of them had launched the incentives to develop more attractive, and competitive urban areas, healthier and more sustainable places to live, by implementing in the same time smart energy technologies. Several policies, proposals and initiatives have been applied or are on the way to be implemented in order to achieve these results as it can be seen in the city agendas and prosumer-related projects.

PICBE $\mid 1127$

\section{Results and discussions}

The smart city concept, along with the technological redevelopment of the urban environment, implies a deep involvement of public institutions, business community and local communities including their citizens. One of the main actors in the smart city will be a citizen living in an environmentally friendly and safe neighborhoods and energy-efficient houses, using affordable and fast transportation and information, taking part in management, improvement, and sharing of smart city incentives and services. The concept of smart city is also inextricably linked to the development of smart energy.

The main trends in the field of smart energy such as the wide spreading of alternative energy sources and digitalization of energy production and distribution increase environmental sustainability, safety of energy supply, reduce energy consumption costs. These trends considered together with the involvement of different actors to the participation in smart city life form a breeding ground for the emersion of prosumers' vision.

There are different forms of organization of prosumers' environment depending on the facility where this initiative was realized, the source of energy used and on the sponsor of the project. One of them is the realization by means of creation of small groups, with individuals or members of a community who carry out prosumer actions, but with the possibility of other members of the community to join and later support these initiatives. Generally, these projects are based in buildings owned by the state social housing. The financing of the implementation of such kind of projects is usually made through state subsidies, but some of them are financed by the alternative financial sources such as crowdsourcing or the contributions collected from the project members. Generally, the plants installed within these projects do not include the electricity storage part, as they are large consumers of electricity and are not supposed to have a surplus. It has been observed that the most used technologies for producing electricity from renewable sources in these projects are hydroelectric, wind power, solar and biomass.

Another form of prosumer is based on the specific utilization of photovoltaic energy. In this case, the micro-generations tend to develop within clusters through which many households will benefit from photovoltaic energy. For instance, the factors that determine the formation of a photovoltaic agglomeration include the location of the site and specific local characteristics, such as the appropriate level of solar irradiation. The formation of a cluster, usually in the case of smart cities, might create the opportunity for the inhabitants to discover the way in which they would support their collective interests by storing the surplus of electricity or by selling it to other persons for a future use.

Electricity exchanges in this case could take place through peer-to-peer services or through dedicated networks that connect directly to prosumers (only if they are legal).

At the household level, the most common facility for the production of electricity appears in the form of photovoltaic panels. This is motivated by the fact that in the last decade, the price of installing photovoltaic panels has decreased significantly, due to its increasing use. This is anticipated to expand even more, due to the increasing promotion of these technologies, as well 
as to the expected advancement of research, development \& innovation within this field. Many states are intending to implement or have implemented economic policies regarding the subsidization of solar energy production systems. It is estimated that the investment in a photovoltaic system recovers within 7 years, by clearing the electricity bills. The manufacturers of solar panels offer a 10-year warranty, but also a performance guarantee that ensures a power of $80 \%$ of the initial value, for at least 25 years (www.engie.ro).

A new evolution of prosumer is made through new business models, which offer different ways for the customer to interact remotely in a win-win relationship in terms of the potential expected benefits obtained. Companies like Piclo, Sonnenbatterie or Yeloha have appeared in response to the new aspirations of energy consumers. These companies offer platforms that allow the transfer of energy from those who have a surplus to those who need it, using peer-to-peer business models. Social entrepreneurs, as well as innovative start-ups, use new smart technologies and ITCs in order to enable users to independently manage consumption and production. Due to the low prices for photovoltaic storage, some specialists support the idea that the electricity grid will reach a "dead line", because the energy formed from renewable sources is traded locally and used to the detriment of energy from conventional sources, which contributes to lower prices in the market.

Since this paper is dedicated mostly to focus on the European practices, the authors consider it is necessary to illustrate the current state of renewable energy development within the European Union member countries, given that it is a driver of prosumers evolution (figure 2).

\section{Share of energy from renewable sources in the EU Member States (2018, in \% of gross final energy consumption)}

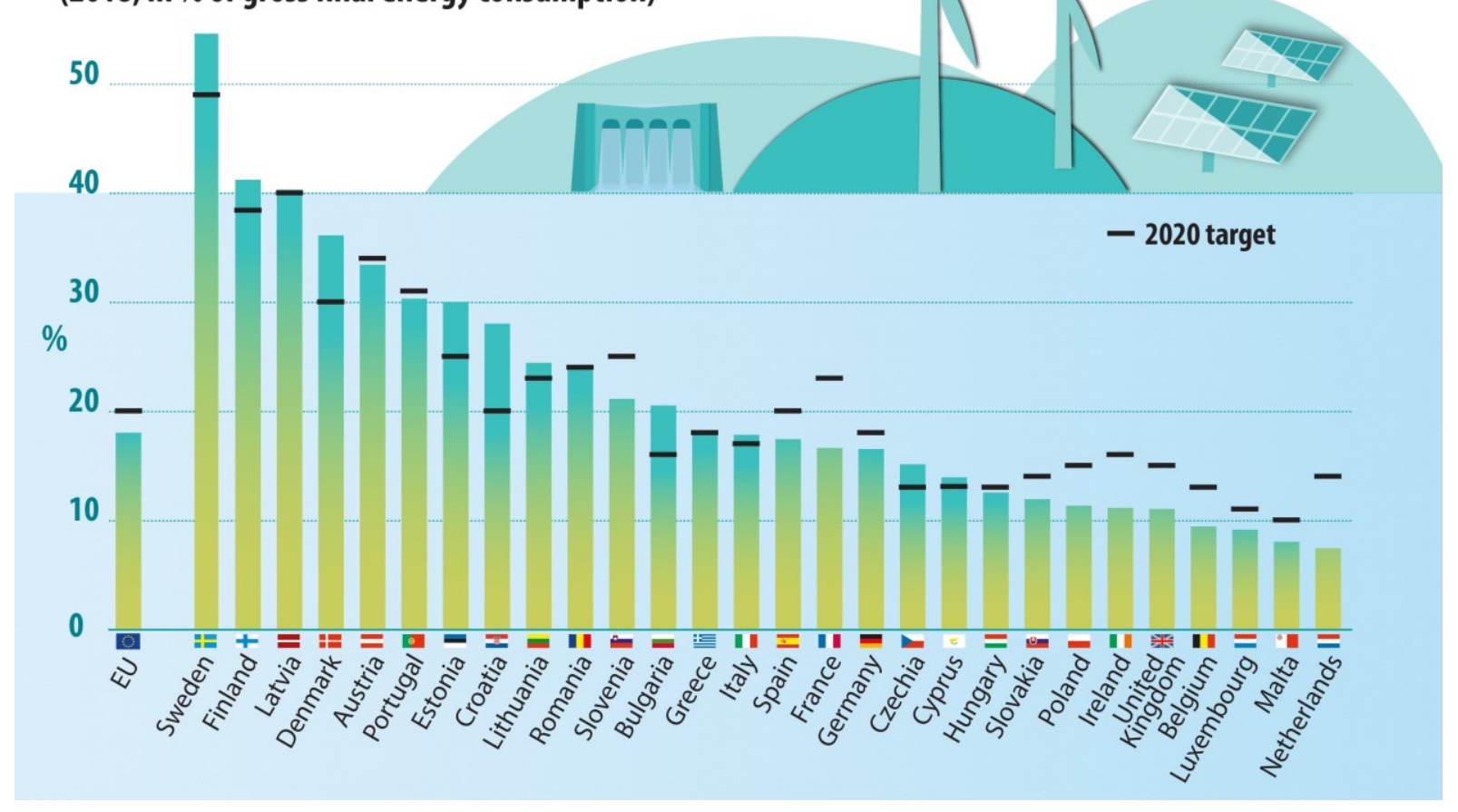

Figure 2. Share of energy from renewable sources in the EU Member States

Source: www.ec.europa.eu. 
Figure 2 shows the share of energy from renewable resources in 2018 in European Union countries. Based on the analysis of the data presented in figure 2, it can be observed that the plan for increasing the consumption of renewable energy has been the most successfully implemented in Sweden, because the share of energy from renewable resources is over $50 \%$. Countries like Latvia and Finland have values close to the 40\% threshold, while, at the opposite end, states such as Luxembourg, the Netherlands, Belgium and Malta, record values below the $10 \%$ threshold. The EU-28 average is just under 20\%, Romania registers about $25 \%$ and Italian indicator is less than $20 \%$.

For 2030, the European Union aims to increase the share of energy from renewable sources from 20\% in 2020, to 32\%. According to the Clean Energy for All Europeans directive European Union aims also to reduce carbon dioxide emissions by about $45 \%$.

In 2014, the average share of solar energy was 2-3\% at European Union level, and the European Commission expects its share to reach $6.5 \%$ in $2020,10 \%$ in 2030 and $13.9 \%$ in 2050, in line with the 2010 political initiatives. It is estimated that by reducing the costs for photovoltaic panels, as well as by supporting the political incentives and objectives for green technologies, will in the future determine an increase in the number of prosumers (IEO,2019). These trends are reflected in the European Union's legislative and non-legislative incentives in favor of development of Smart Cities and green energy. With around 75\% of the European population living in cities, according to World Bank statistics, urban areas in the EU contribute significantly to the EU's energy consumption and greenhouse gas emissions.

This is expected to have a huge impact on the climate change. According to EU policies addressing energy challenges this also mean to promote the development of more attractive and competitive urban areas to be expected to become healthier and more sustainable places to live within. Undoubtedly, the development of Smart Cities and in particular smart energy is directly related to initiatives designed to support sustainability and to enable energy management among citizens. Several policies and initiatives have been implemented to achieve these goals at EU level. For example, the European Commission's 2050 long-term strategy that was adopted in November 2018 presents a long-term vision for a prosperous, modern, competitive and climateneutral economy by 2050. It states that the focus on maximization of the renewables' deployment and increasing demand for electricity will furthermore give an important role to consumers that produce energy themselves (prosumers), and local communities to encourage residential take-up of renewables. The policies supporting the new energy rulebook called "Clean energy for all Europeans package" approved by European Commission in 2019 implies that consumers who take their own decisions on how to produce, store, sell or share their own energy should be placed in the center of EU energy policies.

Taking into consideration the abovementioned issues, the authors have examined the best practices of stimulation prosumer behavior within Italy and Romania.

One of the studies on prosumers in Romania was launched in 2019, within the initiative of a community of prosumers, EnergiaTA, in partnership with Engie. This community has over 5,000 prosumers. Its mission is to facilitate a clean economy based on renewable energy. There are over 7,000,000 households in Romania, and of these, about half could install photovoltaic systems for electricity production. According to the Romanian legislation, prosumers are customers who have installations for the production of electricity, less than $27 \mathrm{~kW}$, whose main activity is not the production of electricity. It can produce electricity for self-consumption, not for commercialization, in the area of houses, industrial or commercial spaces and in blocks. 
Prosumers have to respect both the obligations of consumers, but also those of producers, regarding the network requirements.

In order to stimulate the development of photovoltaic systems, the Government of Romania through the Administration of the Environmental Fund grants financing facilities, respectively a state subsidy for isolated homes, in the amount of 25,000 lei, in a percentage of $100 \%$, only if they are placed at least $2 \mathrm{~km}$ from a connection point.

Another facility is granting at most $90 \%$ of the total value, but not more than 20,000 lei, for those who want to install photovoltaic panels. For granting these facilities, prosumers can settle certain eligible expenses, such as photovoltaic panels, inverter, connection materials, structure of the system mounting, the electrical panel of alternating current electricity or direct current electricity, the (VAT) Value Added Tax on the eligible costs, the smart meter and the communication mode. The purchase of batteries is not subsidized.

Now we will present briefly the cases of Bologna as a smart city example in Italy and correspondingly those of two smart cities from Romania (Alba-Iulia and Cluj-Napoca).

\section{Alba Iulia as a Romanian Smart city example}

The pilot project entitled suggestively "Alba Iulia Smart City", aims to implement and test solutions dedicated to support smart cities vision in the city of Alba Iulia from Romania ( Alba Iulia Smart City, 2019).

The project has some distinguish characteristics in Romania, bringing together government institutions, universities, companies, research institutions and local administration.

The main objectives of the project are the use of technology, information and data capable of responding to the problems related to economic and social development. The project is based on four strategic objectives:

- a creative and competitive city

- a cultural and tourist city

- $\quad$ green city with efficient public services

- a smart and accessible city.

The partners of the project benefit from a high visibility due to a large promotion through the media, but also due to the solutions and results obtained in the online exhibitions.

"Alba Iulia Smart City" has managed to attract many partners who implemented and tested many smart solutions, covering the most important areas of a smart city. Through this project, Alba Iulia benefits from the benefits of new technologies, especially in the creative, communications and IT industries, by testing intelligent solutions that solve certain needs of the local community. The companies, universities and other partners have the opportunity to test the performance of services and products in a real environment. The project is intended to be address to all companies, from the local to the multinational ones, but also to the citizens who want to get involved within it. With the help of this smart city project it is expected an increase in the quality of life of the city inhabitants. One of the examples of smart city, successfully implemented initiative is represented by "Dimlite School Kit". This represents an innovative intelligent lighting system, implemented by Telekom, at School no. 7 "Mihai Eminescu”, from Alba Iulia. This lighting system helps the lighting of the classrooms, as well as the mood of the students. Initially, the lighting system was installed in two classrooms to see the results. Later it was implemented at whole school level. Within each classroom of the school there are special lights 
for the lighting of the boards, these having several scenarios: sunny day, sunny day, semi-night, semi-day and a special protection of the board for the times when the projector is used. The project has brought benefits both at the level of the educational act (such as calming and reassuring the students which ensures a closer relationship between teacher and student, creating a balanced atmosphere between the inner and outer world for creating a pleasant atmosphere), as well as at the level of local administration, respectively low costs of the lighting system and electricity and low risk of injury in case of detachment of the wall bodies, due to the resistant materials from which they are made. Due to the results, the intelligent lighting system was applied in all the 28 classrooms, but also in the school corridors and in the chancellery, secretariat and the board office.

\section{Cluj-Napoca as a Romanian example of smart city}

The city of Cluj Napoca is nicknamed "Sillicon Valley" of Romania, becoming among the first smart cities in Romania. IT companies together with local authorities have succeeded in developing more applications for the citizens of the city.

One of the projects successfully implemented in the city of Cluj-Napoca is represented by the Transnational Renewable Energy Cluster (TREC). The project was developed as a result of global warming and depletion of resources, and to be able to implement policies on sustainable development. In this sense, the development of the production of energy from renewable sources is mandatory. The project consists in the creation and development of a cluster in the field of renewable energy. It want to attract the economic assets that activate in this field, respectively the energy suppliers, but also raw materials for the production of renewable energy, but also energy or equipment producers, research centers, universities that have research activities in this field, companies industrial, energy consultant techniques, financial and banking institutions, professional associations and public authorities that have the role to develop and implement the policy in this field ( Cluj Business)

The implementation of the project brings substantial benefits, both to the city of ClujNapoca and to its inhabitants. The benefits are social, economic, because it will stimulate competitiveness and innovation in the area. Moreover, the project will lead to the cooperation and collaboration of local authorities, companies and research institutions. Companies will acquire skills and know-how in the field of group management, through the transfer of good practices.

Cluj-Napoca' city strategy is focused on the following directions: development of the city based on principle of the quality of life of its inhabitants, balance between economic growth and social cohesion, energy-efficiency, better urban mobility, inclusiveness and safety and efficient and transparent local administration (Cluj Business).

Future projects in of Cluj-Napoca in the framework of energy management within smart city environment are the following: ongoing program of growing the energy efficiency in the buildings within the city; ongoing program of energy evaluation for all public buildings and establishing several investment priorities based on this evaluation; implementing an electronic system of monthly collection of consumption data from the public buildings and creating a data base of the consumption utilities; organizing a common procedure for buying electric energy for all the public buildings in the city, in order to obtain a better price, organizing a local structure with an advisory role reuniting experts from various fields of interest: energy efficiency, private and public sector and NGOs (The Development Strategy of Cluj-Napoca for 2014-2020).

\section{Bologna, as an Italian example of smart city}


Considering the Italian experience in promotion of prosumers' incentives some significant steps have been taken recently on governmental level. In the resolution 7/00022 approved by the Senate of the Republic in June 2019, there is a series of commitments aimed at favoring prosumers starting from the single consumers, groups of consumers, families, local authorities or SMEs that share the self-produced energy.

The resolution calls for the right to produce, consume, store and sell renewable energy to be recognized, without being considered for tax purposes as selling energy.

The resolution also commits the Government to provide a reward mechanism for selfconsumption, and to adopt tax relief measures or capital grants in favor of energy communities and new renewable plants that will operate for local consumption.

In order to illustrate the current state of adoption of measures to provide effective energy management within smart cities in Italy the authors have chosen the case of Bologna: the Metropolitan Strategic Plan (PSM 2.0) of Bologna released in June 2018.

The Plan marks an important change of direction for the development of the entire metropolitan area, providing a unified framework in which governmental institutions, private sector and citizens are aimed to share long-term strategies and medium-term objectives identifying sustainability, inclusiveness and attractiveness as the fundamental dimensions of the plan. These three dimensions are pursued in a cohesive and coordinated manner between the various sectoral policies, and give substance to integrated action both vertically, between different levels of government, and horizontally, seeking the contribution and coordinated actions of all the actors.

The main directions of the following city development according to PSM 2.0 are: the efforts to make Bologna more sustainable, responsible and attractive city; urban and environmental regeneration; better mobility; an emphasis to the development of manufacture and new industries; fostering culture, knowledge, creativity and sport incentives; promotion of an integrated education system and special emphasis on health, welfare and well-being incentives.

Even if there are no specific energetic initiatives mentioned in the Plan, it states that commitment to sustainability is crucially important for improving environmental quality, social well-being of citizens, economic and employment opportunities.

In this context the city of Bologna is committed to achieve the following objectives: to promote the sustainable use of soil, concentrate on urban regeneration, develop the circular economy; adopt measures for climate change adaptation and mitigation, energy saving, improving the quality of air and water, preservation and protection of ecosystems.

One of the projects that justifies these trends is GECO (Green Ecology COmmunity). This project has started in September 2019 and will end in July 2022 ( GECO Community, 2019). The GECO Project, financed by Climate-KiC, coordinated by the Modena Energy and Sustainable Development Agency (AESS), ENEA, the University of Bologna and other Italian institutions, started in July 2019 and aims to promote the generation and self-consumption of renewable energy in the Pillar and Roveri districts of Bologna through the creation of a local energy community, with the involvement of local inhabitants and businesses.

According to the manifest of GECO, the direction in which the project is moving is that of the territorial and energy community, which faces environmental challenges according to the principles of equity and solidarity (GECO Community, 2019 ). The main pillars of the GECO project are: favoring of the autonomy of individuals; reduction of consumption and waste of raw materials; integrating cultural shifts in ecologically sustainable choices, according to the principles of circular economy and conscious consumption; contribution to nurturing and 
strengthening of a community spirit based on collective contribution and active participation in the management of common resources; promotion an inclusive and equitable society to combat the lack of energy (GECO Community, 2019 ).

\section{Conclusion}

All around the world, cities are increasingly investing in technology in order to find solutions to environmental problems, increase sustainability and provide better living conditions for citizens. This is how the phenomenon of smart cities has been arisen.

Strategies for smart cities are represented by urban development policies, which include long-term investments, especially in infrastructure.

Smart cities projects strive to achieve the rapid finding of technological solutions from different fields, especially in those of energy, waste management and transport. But if human capital is not promoted, technology would be useless.

We consider that the development of smart cities must take into account both the technological progress and the development of the knowledge and innovation skills, based on the intelligence and inclusion of people. The smart cities strategies seek to attract the human capital, by offering the government incentives for companies, tax exemptions, financing schemes, opportunities for collaboration with other companies and with the academic environment. Collaboration between companies refers to partnerships for the exchange of knowledge and experience.

Smart cities aim to reduce electricity from conventional sources and produce renewable energy. One of the modalities underlying the production of energy from renewable sources is the installation of photovoltaic panels, and the regular consumers turn into prosumers. They will be able to share the surplus of energy through the intelligent network, which is bidirectional. This is essential in the energy system, because prosumers lead to innovation and value creation in the system. Due to the dynamics of technology, within this field of research it is necessary to identify the most important opportunities, problems and challenges.

The main limitation of our research concerns data applicability. The energy system is very dynamic and the estimated values for the future may modify a lot in time, mostly due to the rapid development of new technologies.

A possible future research direction may take into account a quite polluted city in Europe and suggest some effective \& efficient measures to reduce pollution based both on the models developed in the literature and on a comparative analyses of some best practices concerning modern energy management approaches suitable for smart cities structured on smart grids and similar systems.

\section{References}

Alba Iulia Smart City (2019). Smart City Projects. Retrieved from https://albaiuliasmartcity.ro/en/projects/.

Bosch, P., Jongeneel, S., Rovers, V., Neumann, H. M., Airaksinen, M., \& Huovila, A. (2017). CITYkeys indicators for smart city projects and smart cities. CITYkeys report. Retrieved from https://pdfs.semanticscholar.org/8758/d6c9d7c318e2b4062ff49b5cec3a021f57a1.pdf.

Cluj Business. Cluj-Napoca: Fostering Creativity \& Innovation for a Smart City. Retrieved from https:/clujbusiness.ro/market-overview/business-support/cluj-napoca-fosteringcreativity-innovation-for-a-smart-city/. 
International Energy Outlook ( 2019). International Energy Outlook 2019. Retrieved from https://www.eia.gov/outlooks/ieo/pdf/ieo2019.pdf.

European Commission(2019). Clean Energy for all Europeans. Retrieved from https://ec.europa.eu/energy/en/topics/energy-strategy-and-energy-union/clean-energyalleuropeans $/ /$.

GECO Community (2019). Manifesto. Retrieved from https://www.gecocommunity.it/manifesto/.

PICBE $\mid 1134$

Gharavi,H., \& Ghafurian,R.(2011). SmartGrid: The Electric Energy System of the Future. Proceedings of the IEEE, 99(6), 917-921.

Kubli, M., Loock, M., \& Wüstenhagen, R. (2018). The flexible prosumer: Measuring the willingness to co-create distributed flexibility. Energy policy, 114, 540-548.

Kvellheim, A.K. (2017). The power of buildings in climate change mitigation: The case of Norway. Energy Policy, 110, 653-661.

Morstyn, T., \& McCulloch, M. D. (2018). Multiclass energy management for peer-to-peer energy trading driven by prosumer preferences. IEEE Transactions on Power Systems, 34(5), 4005-4014.

Neumann, H.M., Jakutyte- Walangitang, D., Vielguth, S., Zuger, J., Airaksinen, M., Huovila, A., Bosch, P., Rovers, V., Jongeneel, S., \& Pangerl. E. (2015). Overview of the Current State of the Art. CITYkeys report. Retrieved from

https://www.researchgate.net/publication/331642107_Overview_of_the_Current_State_o f_the_Art.

Parag, Y., \& Sovacool, B.K. (2016). Electricity market design for the prosumer era. Nature Energy, 16032.

Potdar,V., Chandan,A., Batol,S., \& Patel,N. (2018). Big Energy Data Management for Smart Grids-Issues, Challenges and Recent Developments. In Mahmood, Z. (Ed.).Smart Cities (pp. 177-205). Springer, Cham: Switzerland.

Rathnayaka, A.D., Potdar, V.M., Dillon, T., Kuruppu, S.(2015). Framework to manage multiple goals in community-based energy sharing network in smart grid. International Journal of Electrical Power \& Energy Systems, , 73,615-624.

Rathnayaka, A. D., Potdar, V. M., Hussain, O., \& Dillon, T. (2011, December). Identifying prosumer's energy sharing behaviours for forming optimal prosumer-communities. 2011 International Conference on Cloud and Service Computing, 199-206Šajn, N. (2016). Electricity 'Prosumers'. Retrieved from https://www.europarl.europa.eu/RegData/etudes/BRIE/2016/593518/EPRS_BRI(2016)59 3518 EN.pdf.

Toffler, A. \& Alvin, T. (1981). The Third Wave. New York: Bantam Books.

United Nations(2019). Katowice Climate Package: Implementation Guidelines for the Paris Agreement. Retrieved from https://unfccc.int/.

Zafar, R., Mahmood, A., Razzaq, S., Ali, W., Naeem, U., \& Shehzad, K. (2018). Prosumer based energy management and sharing in smart grid. Renewable and Sustainable Energy Reviews, 82, 1675-1684.

Online sources:

https://appsso.eurostat.ec.europa.eu/nui/submitViewTableAction.do (accessed 13 January 2019). https://www.smartgrid.gov (accessed 12 January 2019). 